\title{
Analysis of the Effect of the Space of the Bearing Plate on the Uplift Bearing Capacity of the Concrete Plates-expanded Pile
}

\author{
Qian Yong-Mei ${ }^{*}$ and Zhai Rong-Zheng
}

Institute of Civil Engineering, Jilin Jianzhu University, Changchun, Jilin, 130118, P.R. China

\begin{abstract}
In this paper, using ANSYS FEM software to simulate the failure status of the concrete plates-expanded pile (CPEP) in clay, keeping the other parameters constant, and through changing the space of plate of the concrete platesexpanded pile to study the effect of the space of plate on the uplift bearing capacity of the concrete plates-expanded pile. Through the research of this paper to complete the influence factors of the uplift bearing capacity of the concrete platesexpanded piles, in order to provide theoretical basis to the application of the concrete plates-expanded pile in practical engineering.
\end{abstract}

Keywords: Influence, research and analysis, the concrete plates-expanded pile, the space of the plate, the uplift bearing capacity.

\section{INTRODUCTION}

The study of the uplift bearing capacity of the CPEP is not complete yet, especially for the multiple-disc of the CPEP, and the effect of the space of the plate on the uplift bearing capacity is not explicit, which will hinder the application of the CPEP in practical engineering. In this paper, using ANSYS software to simulate and analyze the failure behavior of the soil surrounding the pile while different space of the plate of the CPEP in clay which is under the effect of the vertical tension, then determine the influence of the space of the plate on the uplift bearing capacity of the CPEP $[1,2]$.

\section{ANALYSIS MODELING}

While study the influence of the space of the plate on the uplift bearing capacity of the CPEP, it is first-line to establish finite element computational (FEM) models of concrete plates-expanded pile of different space of plate (whose units divided as Fig. (1) $[2,3]$. In order to make analysis and comparison of the calculation model easier, the construct of the model has determine principles as follows:

1. According to the earlier research achievement of the CPEP, the length of model pile $\mathrm{L}=8000 \mathrm{~mm}$, the diameter of king pile $\mathrm{d}=500 \mathrm{~mm}$, the diameter of the bearing plateexpanded $\mathrm{D}=1500 \mathrm{~mm}$, the slope toe of the bearing plateexpanded $\theta \approx 37$, the cantilever length of the bearing plateexpanded $\mathrm{R}=500 \mathrm{~mm}$ (the standard of the clear space of pile), the height of the plate $\mathrm{H}=760 \mathrm{~mm}$. What's more, in calculation model, for the sake of avoiding the effect of the boundary constraint conditions on soil, the scope of soil surrounding the pile can't be too small, take diameter as $6000 \mathrm{~mm}$, and depth as $4000 \mathrm{~mm}$ for uplifting.
Due to mainly study the influence of the space of the plate on the uplift bearing capacity of the CPEP, there are two bearing plates-expanded established in calculation model temporarily, fastening the first bearing plate-expanded above the end of pile $1000 \mathrm{~mm}$, other parameters are invariant, only change the position of the other plate-expanded. Because there are effect between the diameter of king pile, plate diameter, plate height, the space of the plate, in order to explain the relative relation exactly and make the study parameter have sense, so the space of the plate takes the clear distance between two bearing plates-expanded, expressed as $\mathrm{S}_{0}$ is shown as Fig. (2), take twice to seventh of $\mathrm{R}, \mathrm{N}$ represents the ratio of $\mathrm{S}_{0}$ and $\mathrm{R}$, then number the pile of $\mathrm{N}=2 \sim 7$ as CE2 CE7 [1]. Making an example of $\mathrm{N}=4$, that is the space of plate is $2000 \mathrm{~mm}$, which the specific model parameter shown as Fig. (2).

The parameter value of constructive CPEP model is as shown in Table $\mathbf{1}$ and Table $\mathbf{2}$.

In order to know the model more visual, giving the model together with pile and soil of the space of the plate as $\mathrm{N}=4$ which is shown as Fig. (3).

\section{ANALYSIS OF THE CALCULATION RESULTS}

\subsection{Analysis of Displacement}

According to the computational formula of the uplift bearing capacity of the double plate of CPEP $[4,5]$ :

$$
F_{\text {pull }}=2 F_{\text {plate }}+F_{\text {side }}+G_{\text {pile }} \text { and } F_{\text {pull }} \leq F_{\text {pile }}^{t}
$$

Due to the formulas above, the uplift bearing capacity of single pile can be calculated preliminarily which is $1067 \mathrm{KN}$, and according to the surface load while loading, start from about $100 \mathrm{KN}$, the latter increase by $100 \mathrm{KN}$ per level [4]. Finally, after calculation, extract each cloud map of vertical displacement of the model separately which is loaded about $1000 \mathrm{KN}$ to analyze. $\mathrm{N}=2 \sim 7$ corresponds the cloud map of the vertical displacement CE2, CE3, CE4, CE5, CE6 and 


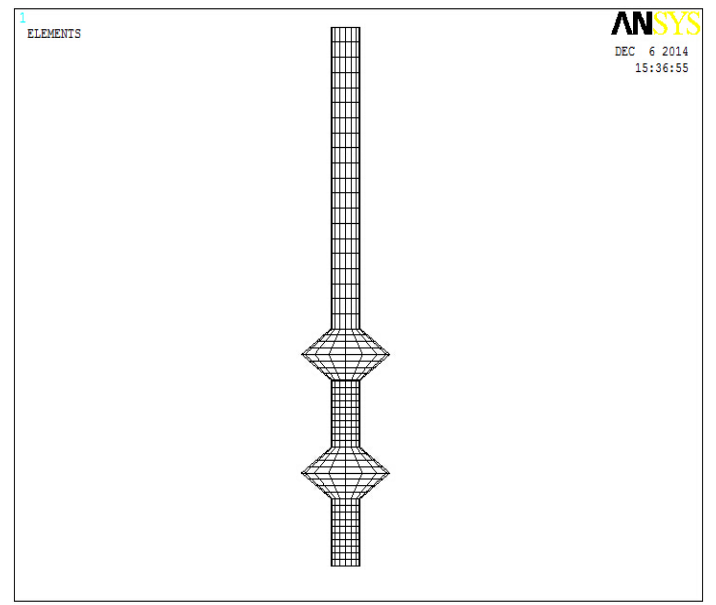

(a) The model of the twice space (GE2)

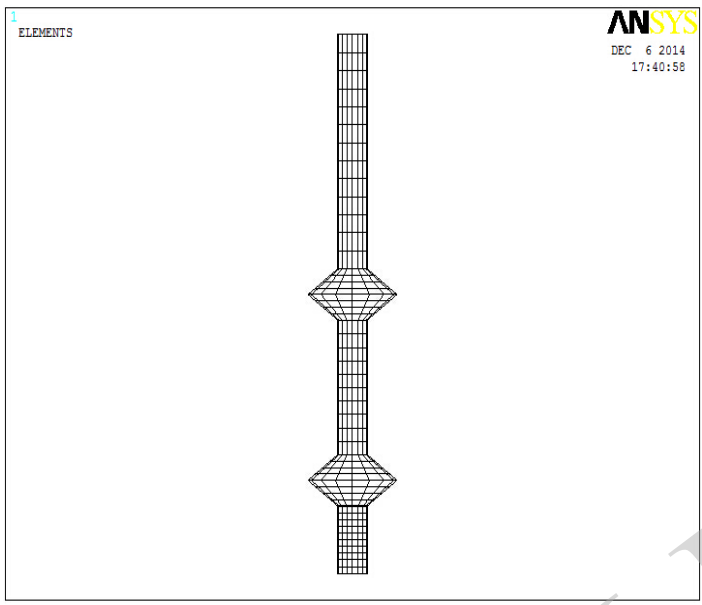

(b) The model of the forth space (GE4)

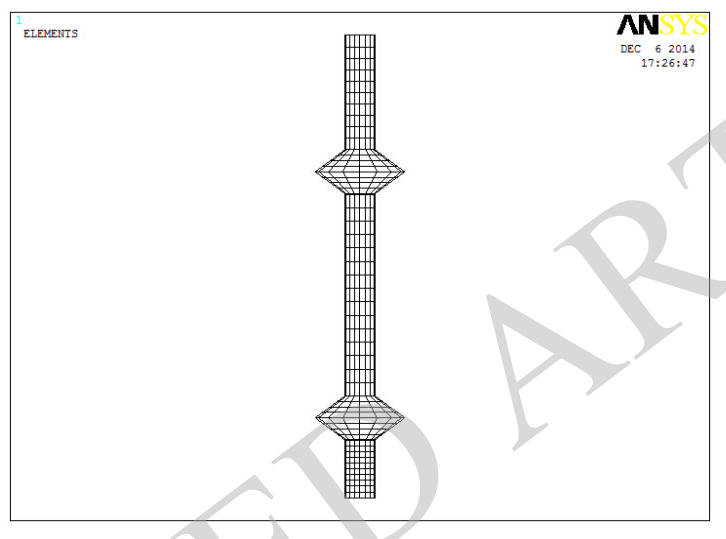

(c) The model of the seventh space (GE7)

Fig. (1). The concrete plates-expanded pile model of different space of the pile.

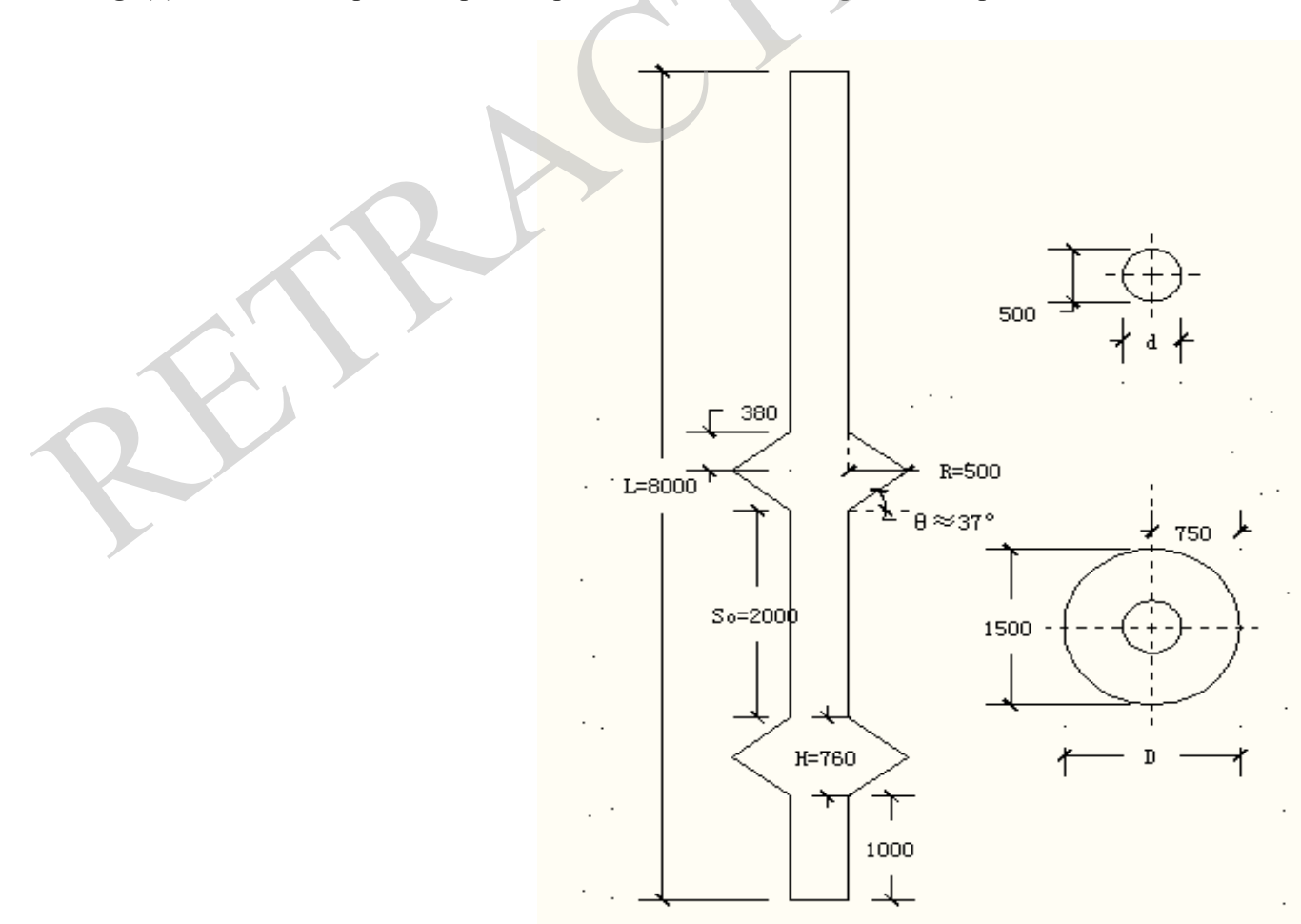

Fig. (2). $N=4$ (CE4) parameter sketch map. 
Table 1. The list of parameter $N$ and $S_{0}$ of each model.

\begin{tabular}{|c|c|c|c|c|c|c|}
\hline Pile number & CE2 & CE3 & CE4 & CE5 & CE6 & CE7 \\
\hline \hline $\mathrm{N}$ & 2 & 3 & 4 & 5 & 6 \\
\hline $\mathrm{S}_{\boldsymbol{0}}(\mathrm{mm})$ & 1000 & 1500 & 2000 & 2500 & 3000 & 3500 \\
\hline
\end{tabular}

Table 2. The list of material parameter.

\begin{tabular}{|c|c|c|c|c|c|c|c|}
\hline MA & DE & EM & PR & C & FA & EA & -- \\
\hline \hline Con & $2.5 \mathrm{e}-9$ & $3 \mathrm{e} 4$ & 0.3 & -- & - & 0.4 \\
\hline clay & $1.9 \mathrm{e}-9$ & 30 & 0.35 & 17.4 & 18.29 & 18.29 \\
\hline
\end{tabular}

Symbol description: MA is the material, DE is the density $\left(\mathrm{t} / \mathrm{mm}^{2}\right)$, EM is the Elasticity modulus (Mpa), FR is the Poisson ratio, C is the cohesion (Kpa) , FA is the Frictional angle $\left({ }^{\circ}\right)$, EA is the Expansion angle $\left({ }^{\circ}\right), \mathrm{CF}$ is the coefficient of friction of piles and soil, Con is the concrete.

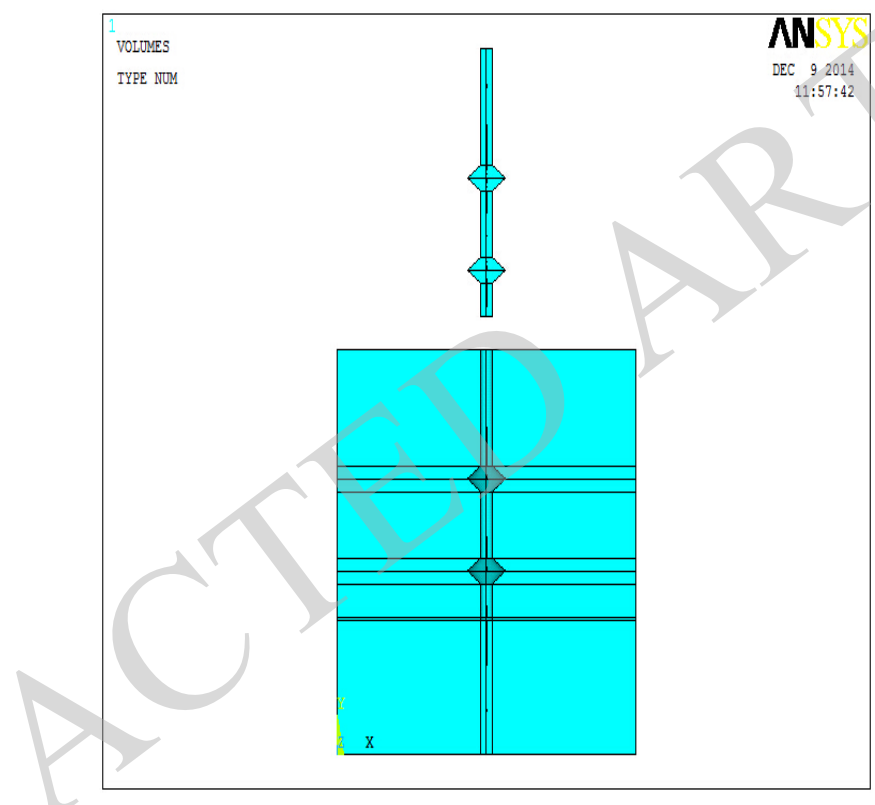

Fig. (3). $\mathrm{N}=4$ (CE4) model of pile and soil.

CE7, giving the cloud map of vertical displacement of CE2, CE4 and CE7 in the following figure, and drawing the maximum displacement value of each model under the same load (about 1000KN) is shown in Fig. (4).

It can be seen from the Fig. (5), when exerting the power nearly reaches the ultimate bearing capacity of the pile, the pile and soil separates and reaches the maximum displacement. It can be seen from the Fig. (5), under the same load, the displacement of pile and soil model of $\mathrm{N}=2$ (CE2) is longer than $\mathrm{N}=3$ (CE3), $\mathrm{N}=4$ ( $\mathrm{CE} 4), \mathrm{N}=5$ (CE5). This is due to when the space of the plate is too small, the soil between two plate may occur punching shear failure entirely, at this time the vertical displacement value approximately more than the displacement of the pile of reasonable space of plate. That can't develop the effect of double plate, so the uplift bearing capacity of pile will decrease. When $\mathrm{N}=7$ (CE7), its vertical maximum displacement will increase, because in the model (CE7), the top of the upper bearing plate-expanded is $1980 \mathrm{~mm}(<4 \mathrm{R})$ from the surface of the soil, and the soil on the plate is easy to occur punching shear failure, this is not good for exert the effect of the bearing plate-expanded either, so this status will decrease the uplift bearing capacity of the concrete plates-expanded pile [6]. It can be known according to all the analysis above, that the effects of the space of plate on the uplift bearing capacity of the concrete plates-expanded pile have two parts, one is the value of the space of the plate, the other is the distance between the top of the bearing plate-expanded and the surface of the soil [7].

\subsection{Analysis of the Curve of Displacement and Load}

Taking the vertical maximum displacement value after loading $100 \mathrm{KN}$ on the model of CE3 CE6 from the ANSYS post-processor, through being settled, drawing the change curve of vertical displacement along with load, which is shown as Fig. (6). 


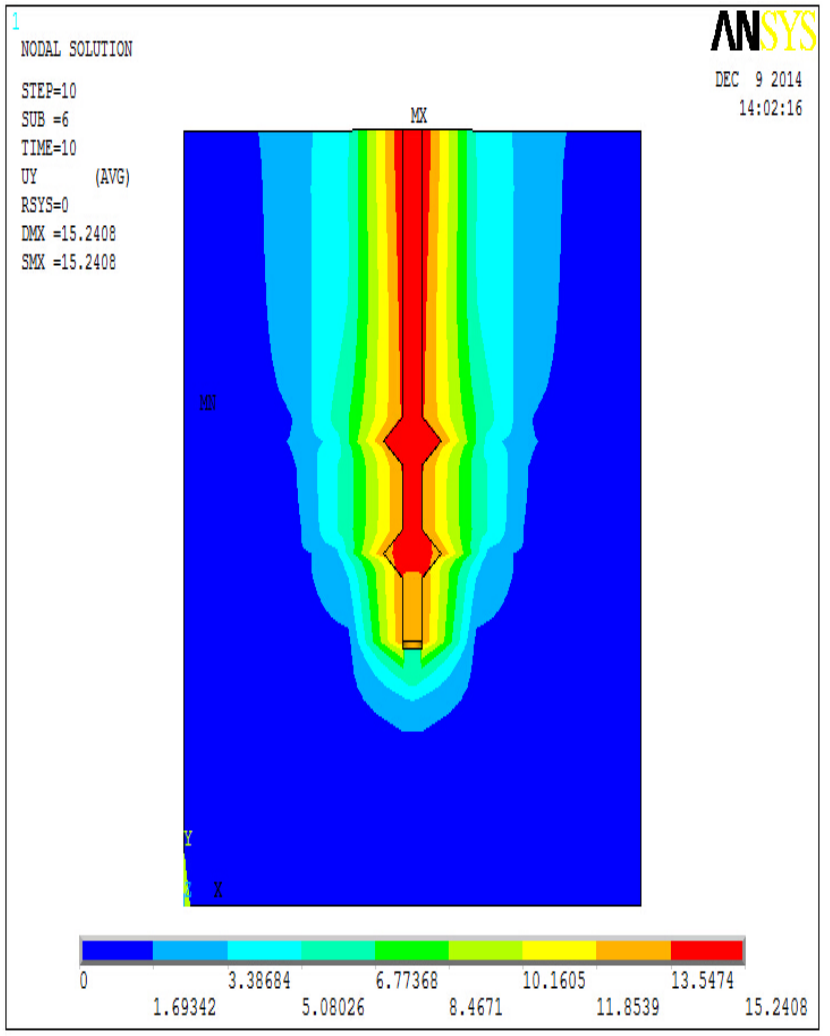

(a) CE2 displacement of pile and soil cloud map

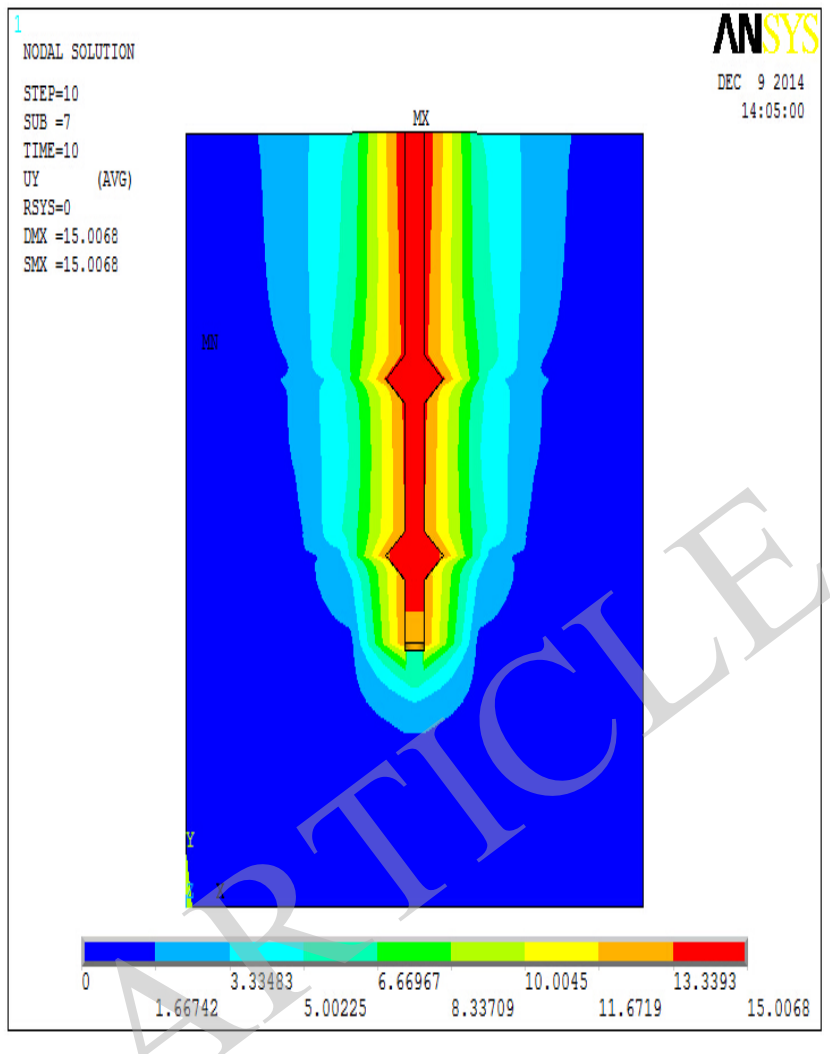

(b) CE4 displacement of pile and soil cloud map

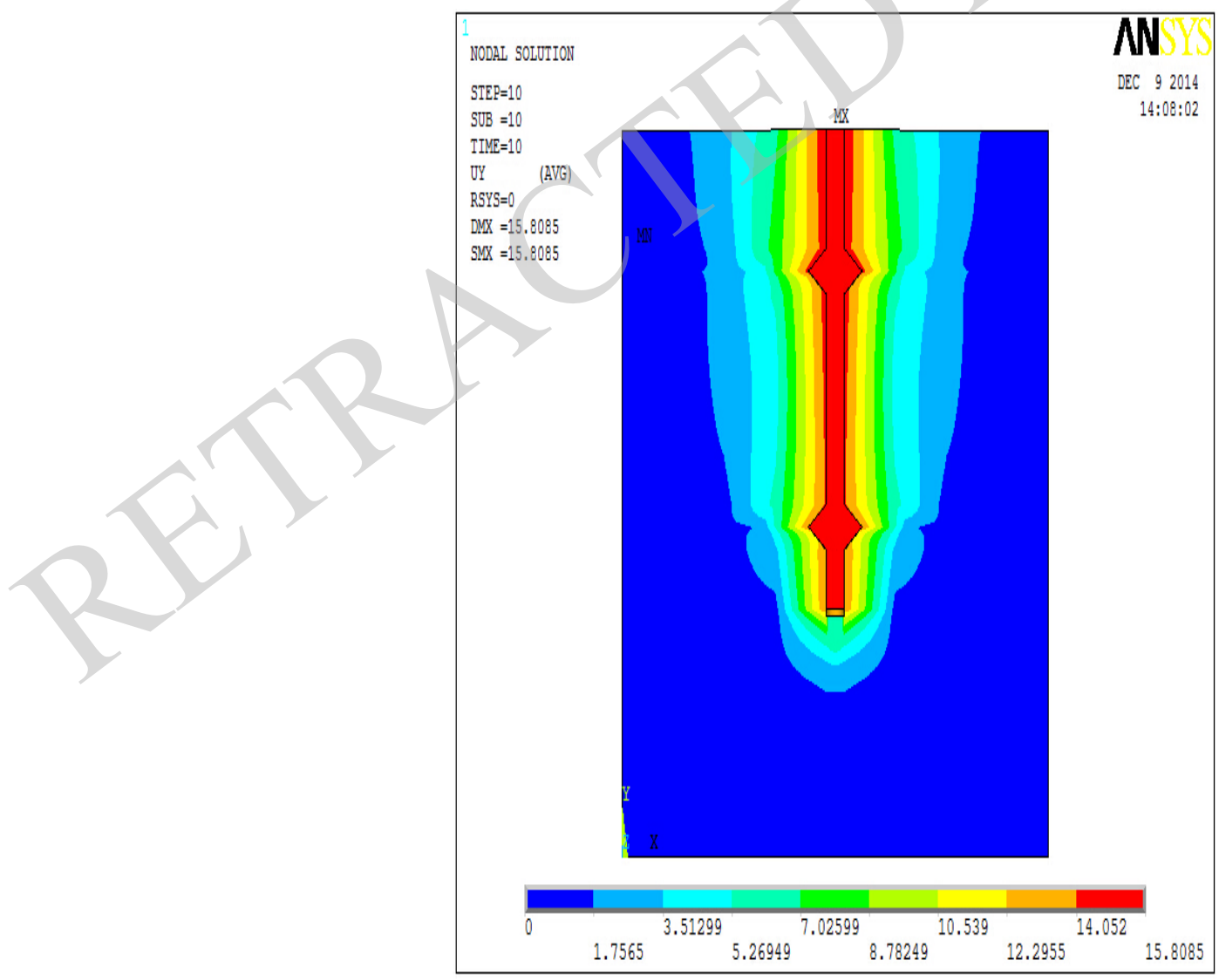

(c) CE7 displacement of pile and soil cloud map

Fig. (4). The cloud map of displacement of vertical pile and soil of different place of plate. 


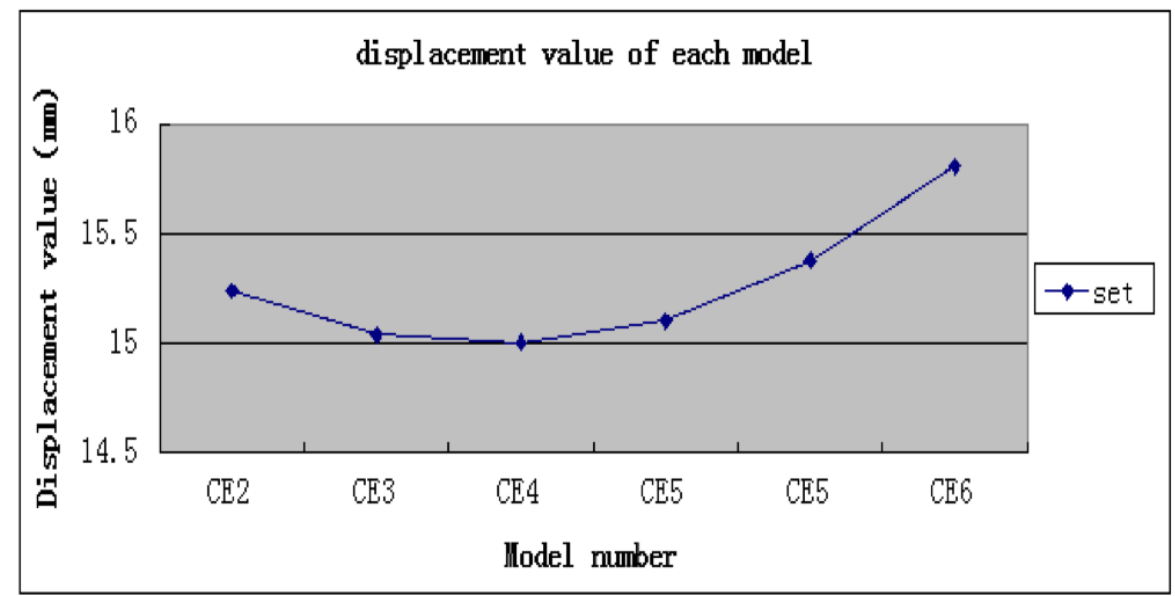

Fig. (5). The vertical maximum displacement value of each model under the same load.

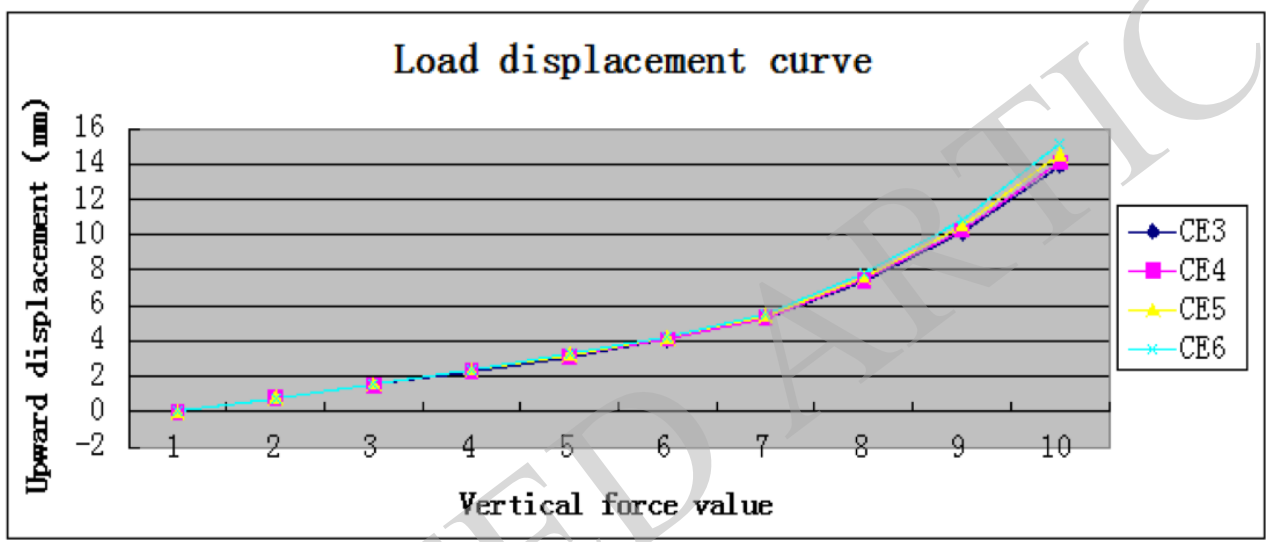

Fig. (6). Change curve of vertical displacement along with load.

It can be seen from Fig. (6), the change rule of vertical displacement along with load of each model is constant, and after loading per level, the vertical uplift value of the model is nearly the same, that is to say, when the space of the plate is more than certain reasonable value $(\geq 3 R)$, along with the increase of load, the changing of vertical displacement of different space of plate of pile is slowly, which explains that the effect on the uplift bearing capacity of the concrete plates-expanded pile is decreasing gradually.

\section{CONCLUSION}

When the concrete plates-expanded pile bear vertical tension, the space of the bearing plate-expanded (including the distance between the top plate to the top surface of soil) is one of important parameters of the design of the concrete plates-expanded pile, it has great influence on the failure behavior of soil surrounding the pile of the concrete platesexpanded pile and the uplift bearing capacity of single pile, so that the reasonable design of the space of plate is very important $[6,7]$. In this paper, the study conclusion is:

1. It can be known from the analysis, in order to let the concrete plates-expanded pile have enough uplift bearing capacity, making sure there is certain distance between the top bearing expanded plate to the surface of soil firstly, normally more than forth of $\mathrm{R}$.
2. When $\mathrm{N} \leq 2.5$, that is the clear space of the bearing expanded plate less than 2.5 times of the length of plate cantilever, the soil between the bearing plate will easily occur failure entirely which make the soil down the bearing plate can not form the sliding failure, it will decrease the uplift bearing capacity of pile, when the space is too long, such as $\mathrm{N}>5$, the length of pile increases too much, while with the increase of the space of the plate, its increase of uplift bearing capacity is too slow which will make the waste of economy. So, it is important to take proper space of plate.

3. The reasonable value range of the clear space of the concrete plates-expanded pile $\left(\mathrm{S}_{0}\right)$ is 3 5 times of the length of plate cantilever $\mathrm{R}$, that is $\mathrm{N}=3 \sim 5$, it will exert the full effect of the bearing pile, and save the project cost.

In addition, due to the soil has effect on the uplift bearing capacity of the concrete plates-expanded pile directly, in this paper only analyzing the influence of the space of pile in clay on the uplift bearing capacity. As for the design parameter of the concrete plates-expanded pile in different areas and soil layer, its effect rule on the uplift bearing capacity is normally the same, but the specific parameters need research deeply.

\section{CONFLICT OF INTEREST}

The authors confirm that this article content has no conflict of interest. 


\section{ACKNOWLEDGEMENTS}

This work was financially supported by National Natural Science Foundation of China (51278224).

\section{REFERENCES}

[1] Y.M.Qian, X.S.Yin, and R.Z.Wang, "The Computer Simulation Analysis of the Effect with Pile and Soil about the Push-ExtendMulti-Under-Reamed Pile", Geotechnical Engineering World, vol 12, pp. 67-70, 2009.

[2] J.A.Wang, S.R.Wang, and J.Y.Feng, "Practical tutorial of geotechnical engineering numerical methods", CA: Beijing, 2010.

[3] Y.M.Qian, N.Mu and R.Z.Wang, "The Research about the Method of Establishing the Model of Limited Unit about the Push-Extend Multi- Under-Reamed Pile", Construction and Urban Planning, pp. 602-605, 2013.
[4] X.Y.Xie, "Research on Ultimate Bearing Capacity and Relationship between Shear and Displacement of Pile-Soil on Push-extend Multi-under-reamed Pile", Jilin Changchun, Jilin University, may, 2011.

[5] Y.M.Qian, X.S.Yin, C.L.Zhong and R.Z.Wang, "The Research on the Ultimate Bearing Capacity of Soil around the Push-extend Multi-under-reamed Pile at Sliding Failure State", Advanced Materials Research, Vols 578-579, pp. 232-235, 2014.

[6] Y.M.Qian, X.Z.CHen, and X.W.Xie, "Determining the Stress Calculation Mode under Sliding Failure of Soil around the Pushextend Multi-under-reamed Pile", Engineering. Vol 6(5), pp. 254259, 2014.

[7] Y.M. Qian, X.S. Yin, R.Z. Wang, and X.X. Yao, "Analysis About the Location of the Bearing Push-extend Reamed of Push-extend Multi-under -reamed Pile Affecting the Bearing Capability of the Pile", Journal of Jilin Institute of Architecture \& Civil Engineering, pp.1-4, 2010.

(C) Yong-mei and Rong-zheng; Licensee Bentham Open.

This is an open access article licensed under the terms of the (https://creativecommons.org/licenses/by/4.0/legalcode), which permits unrestricted, noncommercial use, distribution and reproduction in any medium, provided the work is properly cited. 